\title{
DESCONSIDERAÇÃO DA PERSONALIDADE JURÍDICA UM INSTITUTO DE JUSTIÇA
}

Wesley Aparecido da Silva, Aline Fonseca Franco; José de Oliveira Costa Filho.

Universidade do Oeste Paulista - UNOESTE, Presidente Prudente, SP. E-mail: dpto.adv@gmail.com

\section{RESUMO}

A existência da personalidade jurídica é defendida em especial pela segurança que esta gera aos empresários, sócios, garantindo a autonomia patrimonial dos bens particulares e estabelecendo, como limite para suportar os riscos de qualquer empreendimento, o capital social investido, sendo assim não haveria o risco de comprometimento do patrimônio pessoal do sócio. Ocorre que a personalidade jurídica em diversos casos tomou outro rumo e vem sendo utilizada para prática de ilícitos cíveis, de forma que para coibir esse abuso da personalidade faz-se necessário a existência de um instituto que trate a respeito. É nesse contexto que surge o objetivo da pesquisa, que visa analisar o instituto da desconsideração da personalidade jurídica, quais são seus requisitos para efetiva aplicação, sua real finalidade e efeitos gerados. Ao final conclui-se que o instituto tratado tem pleno e efetivo resultado em desmascarar as fraudes e proteger os credores contra atos ilícitos da pessoa jurídica.

Palavras chave: Sociedade, fraude, personalidade jurídica, desconsideração, credor.

\section{DISREGARD DOCTRINE: A INSTITUTE FOR JUSTICE}

\begin{abstract}
The existence of legal personality is defended in particular the security that brings entrepreneurs and members, ensuring equity autonomy of private property and establishing, as a limit to bear the risks of any enterprise, the capital invested, so there would be no risk to achieve the personal property of the partner.It turns out that the legal personality in many cases took a new direction and has been used for the practice of civil illicit, so that to curb this abuse of personality it is necessary the existence of an institute that treats it. It is in this context that the objective of the research arises, which aims to analyze the disregard of the Institute of legal personality, what are your requirements for effective implementation, its real purpose and generated effects. At the end it is concluded that the treaty institute has full and effective results in unmasking fraud and protect creditors against illicit acts of the juridical person.
\end{abstract}

Keywords: Society, fraud, legal personality, disregard, creditor. 


\section{INTRODUÇÃO}

O lindo sonho de uma criança em colocar uma armadura e sair para o combate na intenção de se tornar um herói, sem medo de ser ferido, é uma realidade no mundo empresarial e jurídico. A personalidade jurídica é essa armadura para os empreendedores que os permitem ter duas personalidades: a da pessoa física e da pessoa jurídica, de forma que quando se está realizando negociações utilizando-se de sua personalidade jurídica, todo o seu patrimônio particular e pessoal ficaria protegido e inalcançável juridicamente.

O problema surge quando esta armadura é utilizada para prática de atos diversos do objetivo para a qual foi construída e, ao perceberem a possibilidade de blindagem de seu patrimônio particular, diversos empreendedores abusam da garantia jurídica em referência, gerando um desequilíbrio para a sociedade.

E é a partir deste ponto que o estudo do instituto heróico surge, qual seja, a desconsideração da personalidade jurídica que visa ultrapassar as garantias da pessoa jurídica e atingir o patrimônio da pessoa física.

Assim, o presente trabalho objetiva fazer um estudo sobre o instituto da desconsideração da personalidade jurídica, seus requisitos de aplicabilidade, sua real finalidade e seus efeitos no plano jurídico, buscando-se ainda avaliar sua efetividade para garantia dos direitos dos credores.

\section{METODOLOGIA}

O presente estudo utilizou o levantamento bibliográficocom abordagem qualitativa e método dialético dedutivo.

\section{RESULTADOS}

A desconsideração da personalidade jurídica teve uma de suas primeiras aplicações em um caso concreto nos Estado Unidos em 1897:

Muito se discute acerca da origem histórica do Instituto da Desconsideração da Personalidade Jurídica. Para a maioria da doutrina, apesar de existir desde o Império Romano - onde, em razão da evolução social, se chegou a conceber, embora timidamente, a subjetividade patrimonial das corporações - o Instituto teve sua origem nos Estados Unidos, em 1809, quando do julgamento do caso Bank of United States v. Deveaux, seguido pelo julgamento do caso Salomon x Salomon CO, em 1897, na Inglaterra. No caso americano, julgado pelo i. juiz Marshall, a teoria da desconsideração foi aplicada para preservar a jurisdição das Cortes Federais sobre as corporations, uma vez que a Constituição Federal Americana, no seu artigo 30 , limita a jurisdição às controvérsias entre cidadãos de diferentes Estados. (BITTENCOURT, 2013, p. 5-6)

Após o julgamento a teoria da desconsideração foi se expandindo, chegando as doutrinas brasileiras, e ganhou espaço no ordenamento jurídico sendo efetivamente incorporada no Código de Defesa do Consumidor de 1990 e no Código Civil 2002.

O Código Civil brasileiro traz o que pode se denominar de conceito a respeito da desconsideração da personalidade jurídica, artigo 50 Código Civil (2002).

Em caso de abuso de personalidade jurídica, caracterizado pelo desvio de finalidade, ou pela confusão patrimonial, pode o juiz decidir, a requerimento da parte, ou do Ministério Público quando lhe couber intervir no processo, que os efeitos de certas e determinadas relações de obrigações sejam estendidos aos bens particulares dos administradores ou sócios da pessoa jurídica. 
O artigo 28 do Código de Defesa do Consumidor (1990) também trata do assunto e apresenta as hipóteses para aplicação da desconsideraçãoda personalidade jurídica da empresa em favor do consumidor, vejamos:

Lei 8.078/90

Art. 28 - O juiz poderá desconsiderar a personalidade jurídica da sociedade quando, em detrimento do consumidor, houver abuso de direito, excesso de poder, infração da lei, fato ou ato ilícito ou violação dos estatutos ou contrato social. A desconsideração também será efetivada quando houver falência, estado de insolvência, encerramento ou inatividade da pessoa jurídica provocados por má administração.

Extrai-se dos artigos que o instituto da desconsideração da personalidade jurídica é o mecanismo pelo qual o credor, quando houver previsão de insatisfação de seus créditos perante à sociedade empresarial devedora, ou seja, na visível possibilidade de não ter seu direito satisfeito e que, por razão da limitação patrimonial conferida à pessoa jurídica, não tenha suas garantias asseguradas, possa descartar essa armadura e adentrar nos bens particulares dos sócios.

A teoria da desconsideração é conhecida na doutrina pela expressão disregarddoctrinee é entendida por Nade (2010) como um ato de abstração da personalidade das pessoas jurídicas que possibilita a extensão da responsabilidade dos administradores ou sócios.

O autor explica que o princípio da desconsideração originou-se nos Estados Unidos da América do Norte e também teve um grande desenvolvimento na Alemanha, sendo que a ideia era coibir toda e qualquer tipo de fraude. O autor também traz outra denominação para a desconsideração da personalidade jurídica: lifting orpiercingtheveil, ou seja, levantando ou perfurando o véu em analogia à função do judiciário de desmascarar a fraude.

Nessa linha, Negrão (2014) cita a utilização do instituto da desconsideração da personalidade jurídica quando se verifica o abuso, vejamos:

[...]abusos por parte do titular da empresa individual de responsabilidade limitada e dos sócios das sociedades, atingindo direito de credores e de terceiros. Nesse caso, vem-se admitindo o superamento da personalidade jurídica com o fim exclusivo de atingir o patrimônio do titular da empresa individual de responsabilidade limitada ou dos sócios da sociedade empresária envolvidos na administração dos negócios. Por essa razão a teoria do superamento da personalidade jurídica - disregardof legal entity - é também conhecida como teoria da penetração.(2014, p. 273)

O autor não generaliza, não mostra que este abuso se tornou praticamente uma regra utilizada pelos empresários ou sócios, apenas entende que estes abusos em determinadas empresas realmente acontecem.

Nas palavras de Dinis (2010, p. 102), a desconsideração poderá ser aplicada:

[...] quando houver confusão patrimonial, em razão de abuso da personalidade jurídica, o órgão judicante, a requerimento da parte ou do Ministério Público, quando lhe couber intervir no processo, está autorizado, com base na prova material do dano, a desconsiderar, episodicamente, a personalidade jurídica, para coibir fraudes de sócios que dela se valerem como escudo, sem importar essa medida numa dissolução da pessoa jurídica. 
A doutrinadora entende que com isso subsiste o princípio da autonomia subjetiva, em cada caso concreto, assim sendo estendida a responsabilidade negocial aos bens particulares dos administradores ou sócios da pessoa jurídica. Tornando assim ineficaz a personalidade jurídica, afastando a fraude perpetrada contra terceiro mediante a utilização da autonomia patrimonial.

Segundo Venosa (2011), quando a personalidade jurídica for utilizada para fugir a suas finalidades, ou seja, com o objetivo de lesar terceiros, deve ser plenamente desconsiderada, assim sendo não deve ser levada em conta a personalidade técnica, deve ser esquecida a sua existência, assim decidindo o julgador como se o ato ou negócio tivesse sido praticado pela pessoa natural. Cita o autor que, na realidade existe a busca de um escudo de legitimidade na realidade técnica da pessoa jurídica, mas o ato seria fraudulento e ilegítimo. Sendo assim, defende ainda que não se trata de considerar sistematicamente nula a pessoa jurídica, mas, em caso especifico e determinado, não levá-la em consideração.

Diante do abuso e da fraude no uso da personalidade jurídica, o juiz brasileiro tem o direito de indagar; em seu livre convencimento, se há de consagrar a fraude ou abuso de direito, ou se deva desprezar a personalidade jurídica, para, penetrando em seu âmago, alcançar as pessoas e bens que dentro dela se escondem para fins ilícitos ou abusivos. (VENOSA, 2011, apud Requião, 1977, v. 2:61)

Cabe mencionar o brilhante entendimento de Coelho (2015) a respeito dos efeitos da desconsideração da personalidade jurídica na validade do ato constitutivo da sociedade e sua limitação ao objeto da fraude, vejamos:

A desconsideração da pessoa jurídica não atinge a validade do ato constitutivo, mas a sua eficácia episódica. Uma sociedade que tenha a autonomia patrimonial desconsiderada continua válida, assim como válidos são todos os demais atos que praticou. A separação patrimonial em relação aos seus sócios é que não produzirá nenhum efeito na decisão judicial referente àquele especifico ato objeto da fraude. Essa é, inclusive, a grande vantagem da desconsideração em relação a outros mecanismos de coibição da fraude, tais como a anulação ou dissolução da sociedade. Por apenas suspender a eficácia do ato constitutivo, no episodio sobre o qual recai o julgamento, sem invalidada-lo, a teoria da desconsideração preserva a empresa, que não será necessariamente atingida por ato fraudulento de um de seus sócios, resguardando-se desta forma, os demais interesses que gravitam ao seu redor. (COELHO, 2015, p. 157)

O autor explica que os atos da sociedade que não são viciados continuam válidos, e a partir do momento da separação patrimonial é o sócio quem irá arcar com as consequências, sendo assim uma grande empresa não será prejudicada caso um ou alguns de seus sócios pratique atos em desacordo com a boa-fé.

O entendimento atual do Superior Tribunal de Justiça é de que, se não houver o abuso plenamente visível não há que se falar em desconsideração da personalidade jurídica, pois o instituto é para dar garantia a credores ou terceiros interessados. Sendo assim não é qualquer ato da sociedade que desagrada os credores que a personalidade jurídica ira perder seus efeitos.

AGRAVO REGIMENTAL. RECURSO ESPECIAL. PROCESSUAL CIVIL. EXECUÇÃO. DISSOLUÇÃO IRREGULAR DA SOCIEDADE. DESCONSIDERAÇÃO DA PERSONALIDADE JURÍDICA. DESCABIMENTO. ART. 50 DO CCB. 1. A desconsideração da personalidade jurídica de sociedade empresária com base no art. 50 do Código Civil exige, na esteira da jurisprudência desta 
Corte Superior, o reconhecimento de abuso da personalidade jurídica. 2. 0 encerramento irregular da atividade não é suficiente, por si só, para o redirecionamento da execução contra os sócios. 3. Limitação da Súmula 435/STJ ao âmbito da execução fiscal. 4. Precedentes específicos do STJ. 5. AGRAVO REGIMENTAL DESPROVIDO.(STJ - AgRg no REsp: 1386576 SC 2013/0177463-0, Relator: Ministro PAULO DE TARSO SANSEVERINO, Data de Julgamento: 19/05/2015, T3 - TERCEIRA TURMA, Data de Publicação: DJe 25/05/2015).

Sendo assim, entende-se que fica a critério do magistrado analisar no caso concreto toda e qualquer possibilidade de fraude, o animus do sócio ou empresário, que pretende violar princípios. A conduta da fraude é algo contra o que a sociedade espera em se tratando de resultados reais, existindo uma confiança que é quebrada quando o agente pratica 0 ato fraudulento e, como o ordenamento jurídico não permite o abuso da confiança, o instituto tratado traz de volta a possibilidade da garantia de justiça, configurando-se o confronto do direito à garantia da pessoa jurídica com o direitodo credor em atuar perante o judiciário para evitar fraudes.

Seguindo o entendimento doutrinário e jurisprudencial acima citados frente à legislação regente da matéria, percebe-se que foi aplicado um grande estudo pelos autores, magistrados, legisladores para tentar solucionar a fraude ocasionada pelo indevido uso da personalidade jurídica, pois a desconsideração se mostrou como um meio efetivo e não traria graves prejuízos à empresa, ao mesmo tempo em que permite que aquele que praticou conduta contraria à esperada seja plenamente responsabilizado.

Esse entendimento é defendido por Bittencourt (2013), conforme abaixo:

O que se percebe hoje é uma forte tendência à coibição dos atos fraudulentos, prestigiando-se sempre o melhor interesse do credor em detrimento dos interesses do devedor - principalmente quando se observa a prática de ilícitos. (BITTENCOURT, 2013, p. 7-8)

É tratado o interesse em prestigiar o credor, mas, de certa forma, o aprofundamento na teoria abrange garantias a toda sociedade.

Adentrando no instituto da desconsideração da personalidade jurídica, verificamos que existem modalidades denominadas Teoria Maior e Teoria Menor. Coelho (2004) trata a respeito da teoria menor da seguinte forma:

A teoria menor da desconsideração é, por evidente, bem menos elaborada que a maior. Ela reflete, na verdade, a crise do princípio da autonomia patrimonial, quando referente a sociedade empresárias. O seu pressuposto é simplesmente o desatendimento de crédito titularizado perante a sociedade, em razão de insolvabilidade ou falência desta. De acordo com a teoria menor da desconsideração, se a sociedade não possui patrimônio, mas o sócio é solvente, isto basta para responsabilizá-lo por obrigações daquela. A formulação menor não se preocupa em distinguir a utilização fraudulenta da regular do instituto, nem indaga se houve ou não abuso. (COELHO 2004, p. 46)

Diante desta teoria não importa se o sócio agiu de forma fraudulenta ou não, uma vez que o objetivo aqui presente é o de não deixar o credor sem receber o que é devido, sendo assim no caso de falência da empresa, o patrimônio dos sócios será atingido independente dos atos praticados. 
De outro lado está a Teoria Maior, sendo seus requisitos apresentados por Silva (2015):

Na Teoria Maior há a autorização da autonomia patrimonial das pessoas jurídicas ser ignorada, como forma de coibir fraudes e abusos praticados através delas. Ocorre que nesta modalidade, deverão ser atendidos alguns requisitos estabelecidos legalmente, e por isso considera-se como uma teoria de maior consistência e que oferece maior segurança aos sócios. (SILVA, 2015).

A Teoria Maior foi adotada pelo código civil, sendo aquela que atinge o patrimônio dos sócios somente quando este agir de forma dolosa nos desvios da finalidade empresaria, a diferença entre as duas teorias é que na menor não existe necessidade de qualquer abuso na ação do sócio ou empresário, basta que a empresa não tenha mais patrimônio para liquidar suas dívidas. A desconsideração será aplicada para garantir direito dos credores. Diferentemente, a teoria maior necessita de requisitos básicos para que o credor possa adentrar no patrimônio pessoal da pessoa jurídica.

Cumpre ainda ressaltarmos a existência da desconsideração da personalidade jurídica inversa, conforme previsão no artigo 133, §2ㅇ do Código de Processo Civil, que, em sentido oposto, confere a possibilidade de se atingir a pessoa jurídica por obrigações dos sócios, quando este atua no sentido de esvaziar o seu patrimônio particular para se livrar de dívidas pessoais contraídas, integrando todo o seu patrimônio pessoal no capital da pessoa jurídica.

\section{CONSIDERAÇÕES FINAIS.}

Diante do exposto, verificamos que o instituto jurídico da desconsideração da personalidade jurídica é meio efetivo para coibir fraudes quando do abuso da personificação de uma sociedade insolvente, permitindo-se o alcance dos bens particulares de sócio para satisfação do direito do credor. Verifica-se ainda que a desconsideração da personalidade jurídica deve ser uma exceção à regra, pois o patrimônio dos sócios é bem particular e não poderia ser atingido, em regra, por dívidas da empresa. Entretanto, em caso de fraude e abuso, o instituo da desconsideração surge como proteção ao credor para levantar esse manto protetivo e ter a plena satisfação de seus direitos.

Por fim, desde que observados os requisitos legais, a desconsideração da personalidade jurídica poderá ser aplicada para equilibrar a balança entre as partes no judiciário: de um lado umaempresa que se tornou ilicitamente insolvente, mas protegida pela armadura da personalidade jurídica e, do outro, o credor que busca satisfação do seu direito.Assim, verificouse, que tal instituto apresenta grande grau de efetividade para tornar ineficazes os atos ilícitos de uma sociedade, alcançando-se o patrimônio dos sócios e seus administradores e, com isso, trazendo garantia de Justiça e pacificação social.

\section{REFERÊNCIAS}

BITTENCOURT. H. A Desconsideração da Personalidade Jurídica A Desconsideração da Personalidade Jurídica - Modalidades e Possibilidade. Rio de Janeiro, 2013. Disponível em: <http://www.emerj.tjri.jus.br/paginas/rcursodeespecializacao latosensu/direito processual civil/ edicoes/n1 2013/pdf/HaynaBittencourt.pdf> Acesso em: 27 de Março de 2016.

BRASIL. Congresso nacional. Código de Defesa do Consumidor.Lei no $\mathbf{8 . 0 7 8}$, de $\mathbf{1 1}$ de setembro de 1990. Dispõe sobre a proteção do consumidor e dá outras providências., Disponível em: <http://www.planalto.gov.br/ccivil_03/leis/L8078.htm>. Acesso em: 06 abr. 2016. 
BRASIL. Congresso Nacional. Código Civil. Lei $\mathbf{n}^{\mathbf{0}} \mathbf{1 0 . 4 0 6}$, de 10 de janeiro de 2002.Institui o Código Civil. Disponível em: <http://www.planalto.gov.br/ccivil 03/leis/2002/l10406.htm>. Acesso em: 06 abr. 2016.

BRASIL. Superior Tribunal de Justiça, Terceira Turma, A desconsideração da personalidade jurídica de sociedade empresária com base no art. 50 do Código Civil exige, na esteira da jurisprudência desta Corte Superior, o reconhecimento de abuso da personalidade jurídica. 2. O encerramento irregular da atividade não é suficiente, por si só, para o redirecionamento da execução contra os sócios. Relator: Ministro Paulo de Tarso Sanseverino, Data de Julgamento: 19/05/2015, Data de Publicação: DJe 25/05/2015)

COELHO, F. U. Curso de Direito Comercial. 7ạ.ed.São Paulo: Saraiva, 2004.

COELHO, F. U. Manual de Direito Comercial: Direito de Empresa. 27ạ.ed. São Paulo: Saraiva, 2015. CURIA, L. R.; CÉSPEDES, L.; NICOLETTI, J. VadeMecum: OAB e Concursos. São Paulo: Saraiva, 2013. DINIZ, M. H. Código Civil: Anotado. 15ạ.ed. São Paulo: Saraiva, 2010.

NADER, P. Curso de Direito Civil: Parte Geral. 7o.ed. Rio de Janeiro: Forense 2010

NEGRÃO, R. Manual de Direito Comercial e de Empresa: Teoria Geral da Empresa e Direito Societário. 11a.ed. São Paulo: Saraiva, 2014.

SILVA, F. P. As teorias maior e menor da desconsideração da personalidade jurídica. 2015. Disponível em: <http://fabianeperess.jusbrasil.com.br/artigos/205854963/as-teorias-menor-emaior-da-desconsideracao-da-personalidade-juridica> Acesso em: 27 de Março de 2016.

VENOSA, S. S. Direito Civil: Parte Geral. 11a..ed. São Paulo: Atlas, 2011. 